\title{
Design and Performance Analysis of Asymmetrical U-Slot Circular Patch Antenna for Wimax and WLAN Applications
}

\author{
Arshad Wahab*and Xu Jiadong \\ Northwestern Polytechnic University, 710129, Shaanxi, Xian, China \\ arshadwahab90@gmail.com
}

\begin{abstract}
The dual U-slot and tri-U-slot patch antennas have been designed to operate in WiMAX and WLAN applications. The radiation parameters such as return los ryadiation patterns, VSWR, and gain of the antennas have been analyzed using CST microwave studio. The proposed antennas have simple structure, simple coaxialfeed, inexpensive, ease of fabrication and light weight designed for realizing anal band characteristics. The dual $U$-slot antenna has the bandwidths of $0.27 \mathrm{GHz}$ and $0.47 \mathrm{GK}$ ranging $3.37 \mathrm{GHz}$ to $3.64 \mathrm{GHz}$ and $5.15 \mathrm{GHz}$ to $5.62 \mathrm{GHz}$ respectively. The tri-U-slol antenna has the bandwidths of $0.14 \mathrm{GHz}$ and $0.66 \mathrm{GHz}$ ranging from $3.61 \mathrm{GHz}$ to $3.71 \mathrm{GHz}$ and $5.18 \mathrm{GHz}$ to $5.84 \mathrm{GHz}$ respectively. The gains of the dual N-lots antenna have $8.77 \mathrm{dBi}, 9.47 \mathrm{dBi}$ and $8.1 \mathrm{dBi}$ and tri-U-slot antenna have the gams of 8.71dBD8.66dBi and $9.09 \mathrm{dBi}$ at the operating frequencies of $3.67 \mathrm{GHz}, 5.2 \mathrm{GHz}$ and $5.8 \mathrm{GHz}$ respectively. The simulated and measured results show that the antennas have stable gains, good impedance matching and directional radiation patterns. The measuredy and simulated results are in good agreement.
\end{abstract}

Keywords: U-slot, WLAÂ, Circular Patch, WiMAX

\section{Introduction}

The patch antennas having w -slot with linear polarizations have been introduced for various wireless conmunication applications such as mobile phone, WLAN, WiMAX, Bluetooth etc. For modern wireless communications need simple, multifunction and loy cost antenna. The U-slot antenna presented in paper showed wideband behayior and linearly polarized [2]. Initially, U-slot was used for obtaining only Wideband characteristics instead of multiband characteristics. Recently many-researches show that multiband characteristics can be achieved by intelligent adjustment of the U-slot [1,3]. Besides the band characteristics the polarization characteristics can be adjusted by optimization of U-slot. The antenna presented in $[4,5]$ exhibited circular polarization. The length of the U-slot length has been changed with pin diode which causes to switch between circular and linear polarization state as well as to switch between left hand and right hand circular polarization [6].The dual band and tri-band performances has been obtained by cutting U-slot in the patch.

\section{Antennas Configuration}

The u-slot was made of two vertical and a horizontal rectangular slot in the patch to obtain broadband performance. The geometry of the antennas having variable dimensions is shown in the Figure1. The final optimized parameters of proposed designs are listed in Table 1 and Table 2. The antennas comprise of dual U-slot and tri U-slot, which were cut in the single layer of circular patch. The dimension of the ground is $50 \times 50 \mathrm{~mm}^{2}$ and made of copper plate placed under the patch. Air is used as the substrate of thickness $h=5 \mathrm{~mm}$. 
The coaxial probe having SMA connector of inner and outer diameter of $0.6 \mathrm{~mm}$ and $2 \mathrm{~mm}$ respectively, this is directly connected to the patch. The thickness of the substrate is the same in both designs.
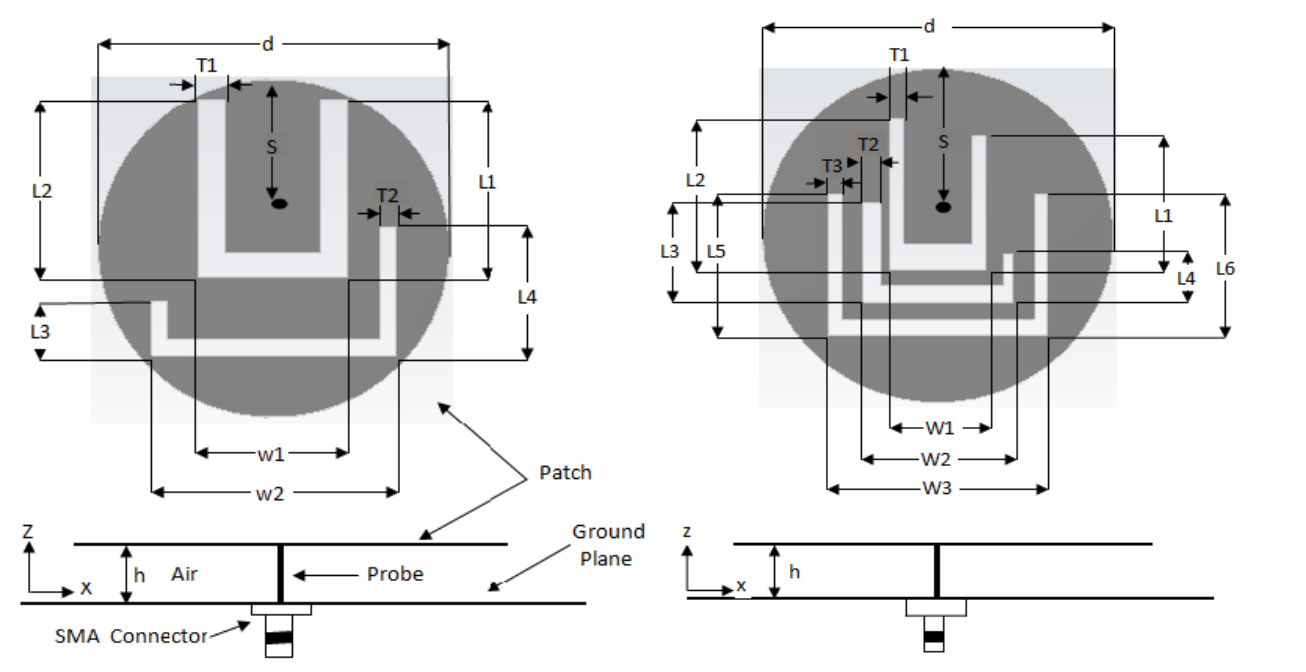

Figure 1. Geometry of (a) Dual U-Slots (b) Tri-U-Slot Patch Antenna

In the proposed designs full ground plane is used which reflects most of the electromagnetic waves back to the patehsurface

Table 1. Parameters of Dyal U-Slot Antenna

\begin{tabular}{|c|c|c|c|c|c|c|c|}
\hline $\mathrm{L}_{1}$ & $14 \mathrm{~mm}$ & $\mathrm{~L}_{4}$ & $11 \mathrm{~mm}$ ? & $\overline{\mathrm{W}_{1}}$ & $23 \mathrm{~mm}$ & $\mathrm{~d}$ & $16.5 \mathrm{~mm}$ \\
\hline $\mathrm{L}_{2}$ & $15 \mathrm{~mm}$ & $T_{1}$ & $2.5 \mathrm{~mm}$ & $\mathrm{~W}_{2}$ & $15 \mathrm{~mm}$ & $\mathrm{~h}$ & $5 \mathrm{~mm}$ \\
\hline $\mathrm{L}_{3}$ & $3.8 \mathrm{~m}$ & & $1.5 \mathrm{~mm}$ & $S$ & $3.8 \mathrm{~mm}$ & & \\
\hline
\end{tabular}

Table 2. Parameters of Tri-U-Slot Antenna

\begin{tabular}{|c|c|c|c|c|c|c|c|c|c|}
\hline $\mathrm{L}_{1}$ & $13 \mathrm{~mm}$ & $P_{4}$ & $3.8 \mathrm{~mm}$ & $\mathrm{~T}_{1}$ & $3 \mathrm{~mm}$ & $\overline{\mathrm{W}_{1}}$ & $11 \mathrm{~mm}$ & S & $5 \mathrm{~mm}$ \\
\hline $\mathrm{L}_{2}$ & $15 \mathrm{~mm}$ & $\mathrm{~L}_{5}$ & $15 \mathrm{~mm}$ & $\mathrm{~T}_{2}$ & $2 \mathrm{~mm}$ & $\overline{\mathrm{W}_{2}}$ & $17 \mathrm{~mm}$ & $\mathrm{~d}$ & $20 \mathrm{~mm}$ \\
\hline $\mathrm{L}_{3}$ & $10 \mathrm{~mm}$ & & $15 \mathrm{~mm}$ & $\overline{\mathrm{T}_{3}}$ & $2 \mathrm{~mm}$ & $\overline{W_{3}}$ & $23 \mathrm{~mm}$ & $\mathrm{~h}$ & $5 \mathrm{~mm}$ \\
\hline
\end{tabular}

\section{Results and Discussion}

EST Microwave Studio, commercial electromagnetic simulation software has been used to perform the simulation of the proposed antenna designs. The antenna performance depends on different parameters. By changing the parameters of the proposed designs variation in the antenna characteristics have been observed by numerous simulations perform in CST simulator in order to confirm the results. The antennas have been parametrically studied and investigated the relations between the lengths, broadness and positions of the U-slots on the patch surface. The return loss of the antennas is demonstrated in the Figure 2. The measured reflection coefficient of tri-U-slot antenna is shown in Figure 4 which shows good agreement with the simulated return loss. The sharp edge of each curves represent the desire frequency band. The proposed antennas have good impedance matching as their return loss is sufficiently below -10db at all resonance frequencies. The dual U-slot antenna has the bandwidth of $0.27 \mathrm{GHz}$ ranging from $3.37 \mathrm{GHz}$ to $3.64 \mathrm{GHz}$. The bandwidth is sufficient to accommodate in the WiMAX standard. The second band of dual U-slot antenna has the bandwidth of $0.47 \mathrm{GHz}$ ranging from $5.15 \mathrm{GHz}$ to $5.62 \mathrm{GHz}$. This would allow WLAN and WiMAX operations. On the 
other hand the first band of tri-U-slot antenna has the bandwidth of $0.14 \mathrm{GHz}$ ranging from $3.61 \mathrm{GHz}$ to $3.75 \mathrm{GHz}$, which falls in the WiMAX and IMT operations. While the second band of tri-U-slot antenna has the bandwidth of $0.66 \mathrm{GHz}$ ranging from $5.18 \mathrm{GHz}$ to $5.84 \mathrm{GHz}$, which is suitable for WLAN and WiMAX applications.
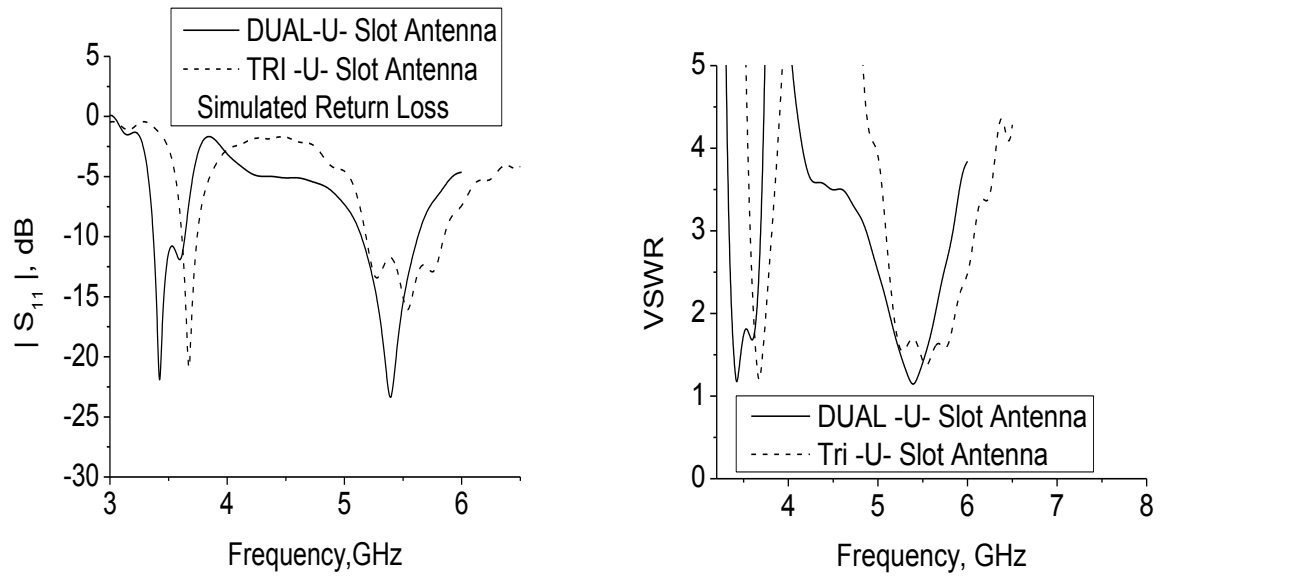

\section{Figure 2. Simulated Reflection Coefficient and VSWR of Dual U-Slot and Tri- U-Slot Antenna}

The VSWR of proposed designs are shown in the Figure2. The VSWR of dual U-slot have $1.10,1.08$ and 1.11 at the resonanee frequencies of $3.6 \mathrm{GHz}, 5.2 \mathrm{GHz}$ and $5.8 \mathrm{GHz}$ respectively. The tri-U-slot has the $5 \mathrm{SWR}$ values of $1.10,1.15$ and 1.15 at the central frequencies of $3.6 \mathrm{GHz}, 5.2 \mathrm{GHz}$ and $5.8 \mathrm{GHz}$ respectively.
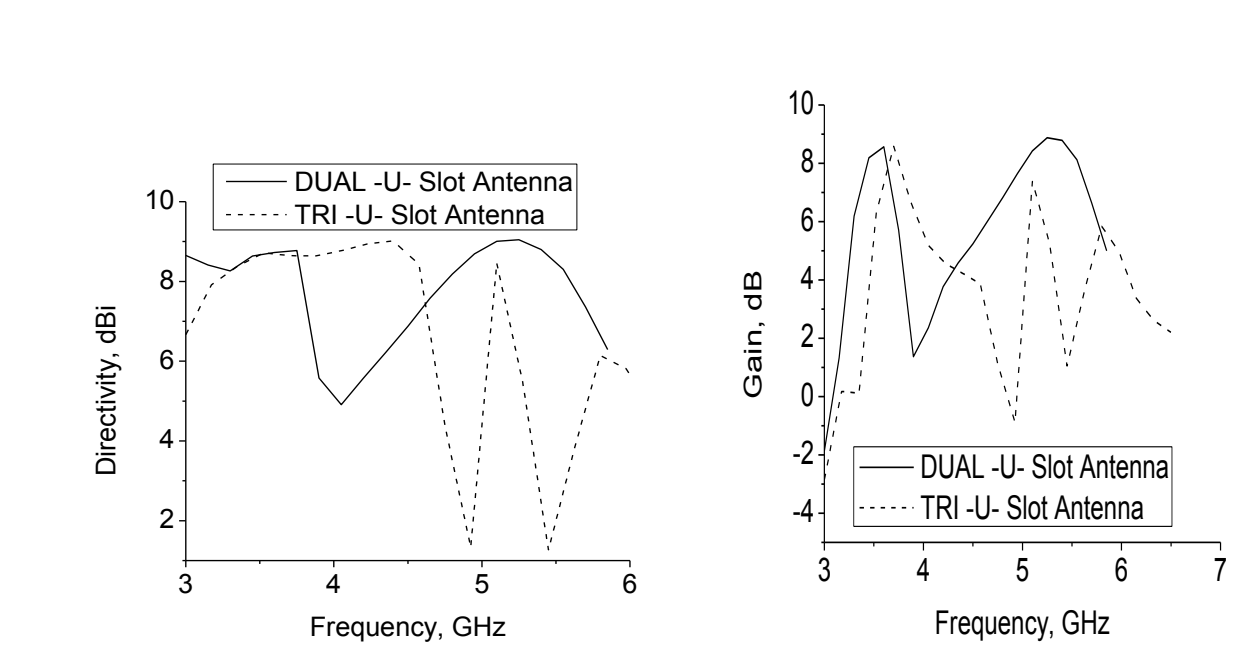

Figure 3. Directivity and Gain of Dual U-Slot and Tri U-Slot Antenna

The gain and directivity of the proposed designs are shown in the Figure3. The directivities of the dual U-slot antenna at the resonance frequencies of $3.6 \mathrm{GHz}, 5.2 \mathrm{GHz}$ and $5.8 \mathrm{GHz}$ are $8.773 \mathrm{dBi}, 9.473 \mathrm{dBi}$ and $8.103 \mathrm{dBi}$. While that of tri-U-slot antenna have the directivities of $8.712 \mathrm{dBi}, 8.655 \mathrm{dBi}$ and $9.091 \mathrm{dBi}$ at the central frequencies of $3.6 \mathrm{GHz}$, $5.2 \mathrm{GHz}$ and $5.8 \mathrm{GHz}$.

The parameters which are capable of improving the gain of the antenna are the dielectric constant, distance of the u-slot from the lower side of the patch, broadness and the length of the u-slot. The effect on the return loss of dual-U-slot antenna for different values of $\mathrm{L}_{3}$ and $\mathrm{S}$ are shown in Figure 5. And the frequencies shifting for different values of $\mathrm{S}$ and position of third slot of tri-U-slot antenna are shown in Figure6. 

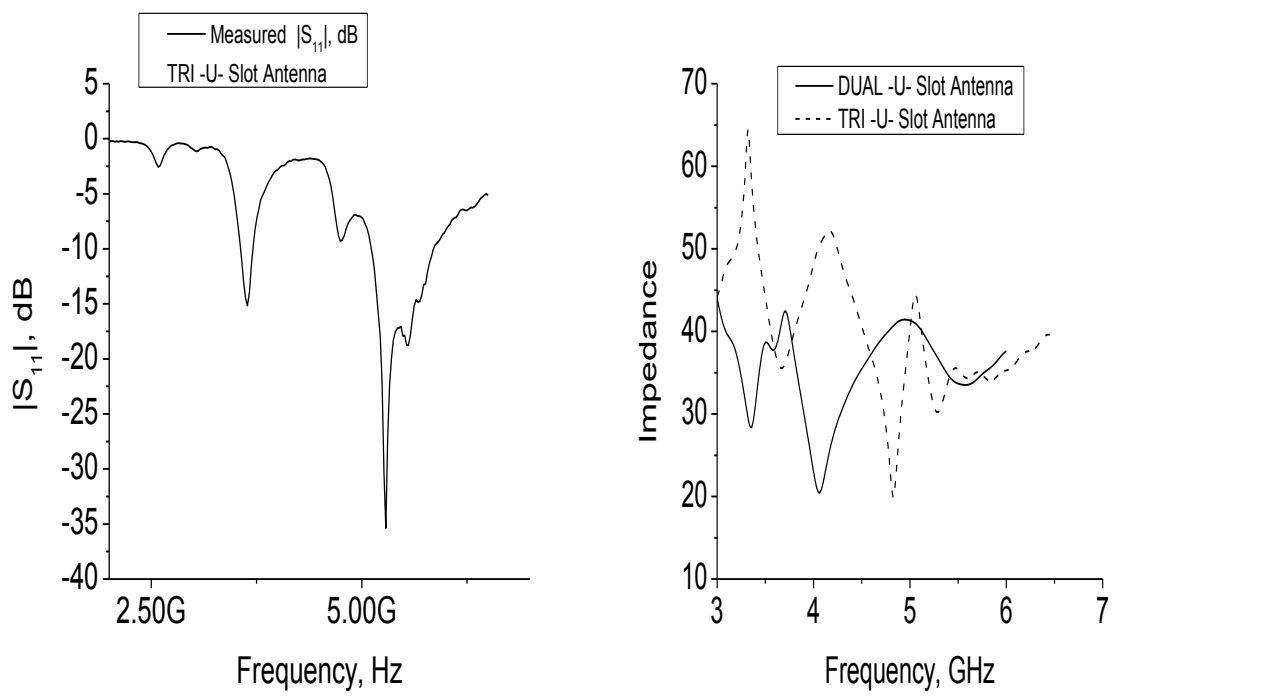

Figure 4. Measured Reflection Coefficient of Tri-U-Slot Antenna and Simulated Input Impedance of Dual U-SIOl and Tri-U Slot Antenna

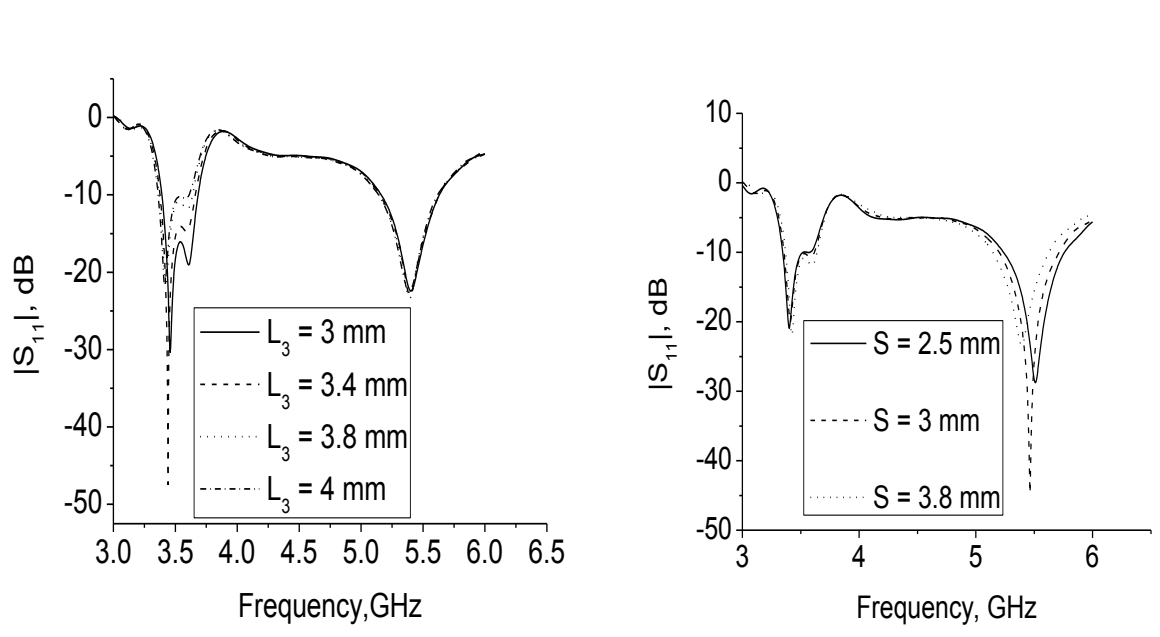

Figure 5. Simulated Reflection Coefficient for the $L_{3}$ and $S$ of Dual U-Slot Antenna

These parameters are adjusted and bring improvement in the gain of the antenna. The simulated gains have sufficiently high for desire performance of the antennas. The improvement in the gain and directivity of the antenna is because of using air substrate. The gains of the antenna are also affected by the dimensions of the patch and the ground. When the ground and patch have same dimensions, the antennas gains decrease and with increasing the size of the ground the gains increase. The size of the ground affects the antennas gain up to $50 \mathrm{~mm}$. So higher gains are obtained on considering $50 \times 50 \mathrm{~mm}^{2}$ dimension of the ground plane. The simulated gains of dual U-slot antenna have calculated which are $8.77 \mathrm{dBi}, 9.47 \mathrm{dBi}$ and $8.1 \mathrm{dBi}$ at the resonance frequencies of $3.6 \mathrm{GHz}, 5.2 \mathrm{GHz}$ and $5.8 \mathrm{GHz}$ respectively. 

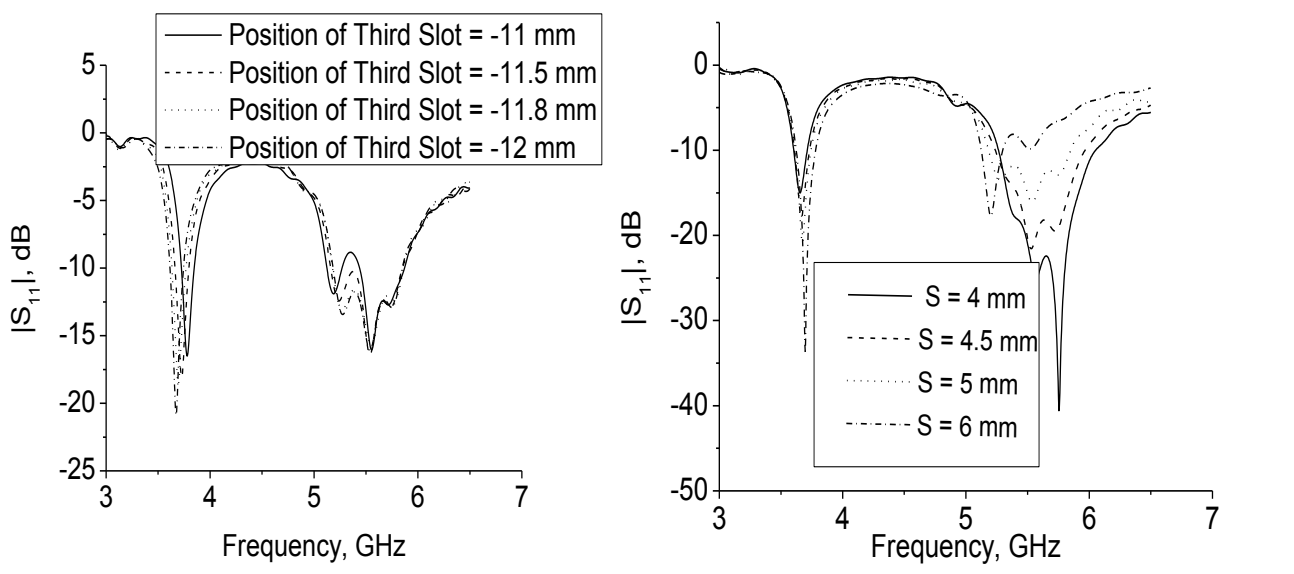

Figure 6. Simulated Reflection Coefficient for the Position of the Third Slot and S of Tri-U-Slot Antenná

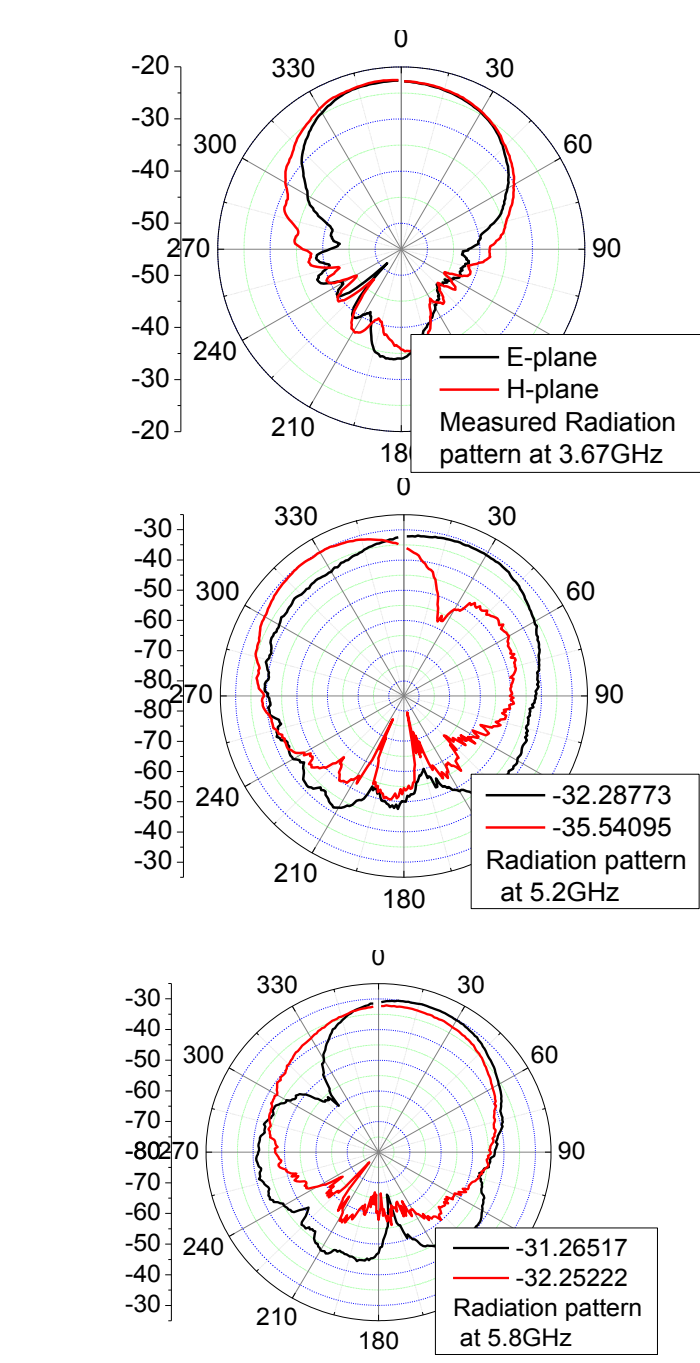

(a)
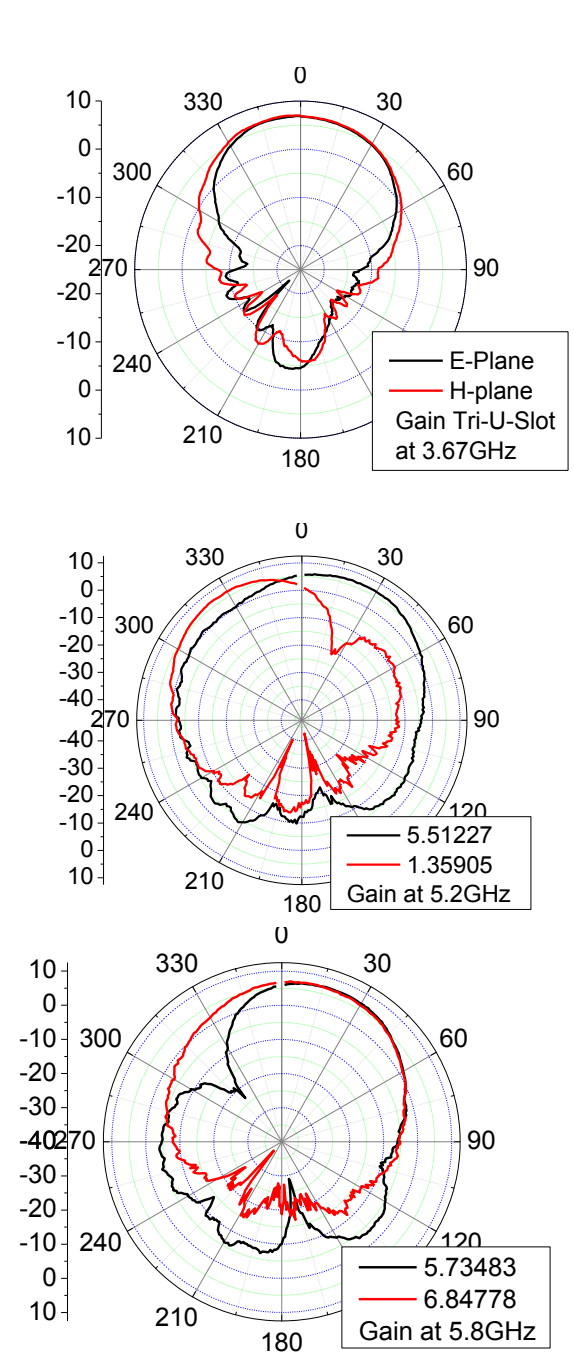

(b)

Figure 7. Measured Radiation Patterns E-Plane and H-Plane (B) Measured Gains E-Plane and H-Plane at 3.67ghz, 5.2ghz, and 5.8ghz 

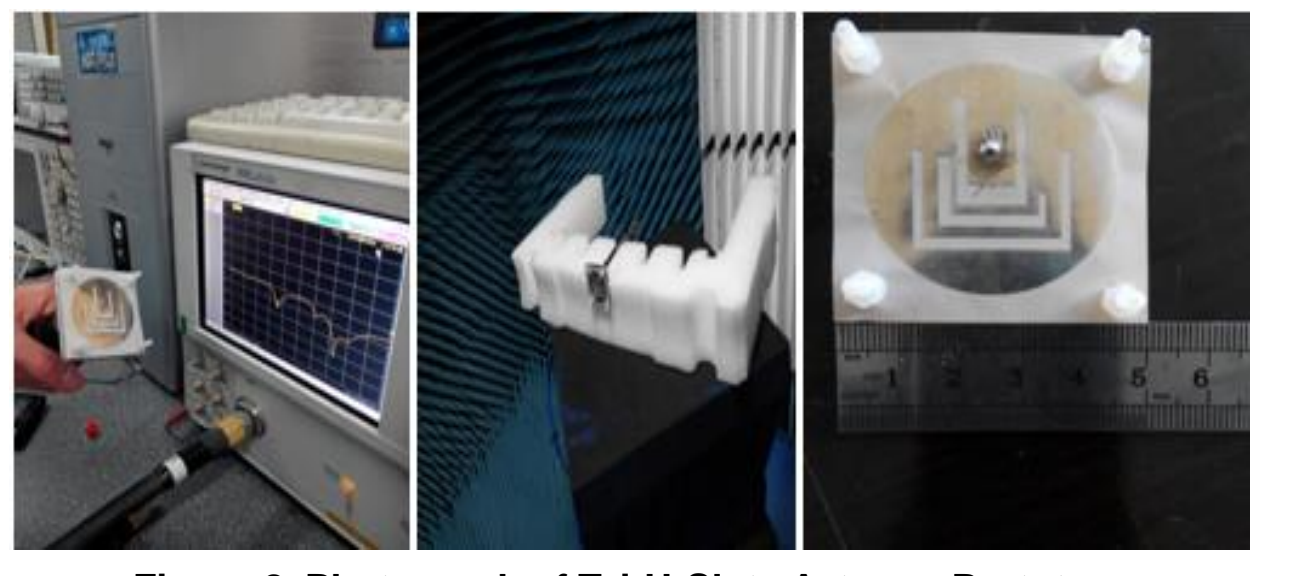

Figure 8. Photograph of Tri-U-Slots Antenna Prototype

The measured gains and radiation patterns E-plane and H-plane of tys $\mathrm{U}$-slot antenna at the resonance frequencies of $3.6 \mathrm{GHz}, 5.2 \mathrm{GHz}$ and $5.8 \mathrm{GHz}$ are demonstrated in the Figure 7. The photographs of tri-U-slot antenna are shown in the Figure8.

\section{Conclusion}

The proposed designs have simple geømetries of a Single-layer single-patch dual band patch antennas. The antennas have stable radiation patterns throughout the operating frequencies. The dual U-Slot and tri- 1 -slots patch antennas have been design to cover the upper and lower band of WLAN and WiMAX operating frequencies. In order to achieve the require d gain the proposed design can be used to form an array. The fabricated antenma has been analyzed in term of radiation patterns, gain and return oss which is suitable for wireless applications.

\section{References}

[1] T. Huynh and K.F. Lee, "Single-lay en single-patch wideband micro-strip antenna", Electronics letters, vol. 31, (1995), pp. 1310-1312.

[2] Y. X. Guo, K. M. Lûk K. F. Lee and Y. L. Chow, "Double U-slot rectangular patch antenna", Electronics Letter, vol. 34, (1998), pp. 1805-1806.

[3] K. F. Lee, S. Yang and A. A. Kishk, "Dual and multiband U-slot patch antenna", IEEE Antennas Wireless Propagation, vol. 7, (2008), pp. 645-647.

[4] K. F. Lee, K. M., Euk T. and M. S. Yang, "Dual and triple band stacked patch antennas with U-slot", Proceeding( of Forth European Conference on Antennas and Propagation (EuCAP), Bercelona, Spain, (2010), pp $1-5$.

[5] S. Yarg, K. F., Lee, A. A. Kishk and K. M. Luk, "Design and study of wideband single feed circularly polarized micro-strip antenna", Progress in Electromagnetic Research, vol. 80, (2008), pp. 45-61.

[6. F. Tong and T. P. Wong, "Circularly polarized U-slot antenna", IEEE Trans. Antennas propagation, vol. 55, (2007), pp. 2382-2385.

\section{Authors}

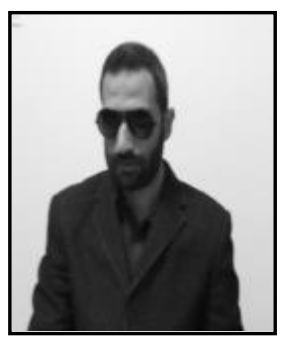

Arshad Wahab, Engineer, he is a student of $\mathrm{PhD}$ in the school of Electronics and information's at North western Polytechnic University, Xian China. The main research fields are Antenna design and electromagnetic. 


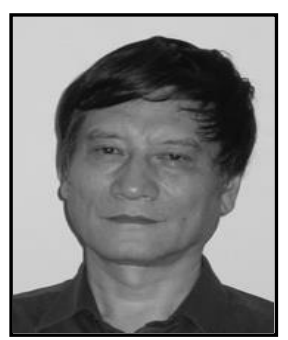

Xu Jiadong, he is Professor in the school of Electronics and information's of North Western Polytechnic University, Xian China. He did MSc in 1981. He received many awards such as National Special Allowance of award, Title of Expert of Aeronautical of ministry, First class award of Guanghua, and First class award of Astronautic science. Altogether more than 180 publications in the fields of Electronics and information.

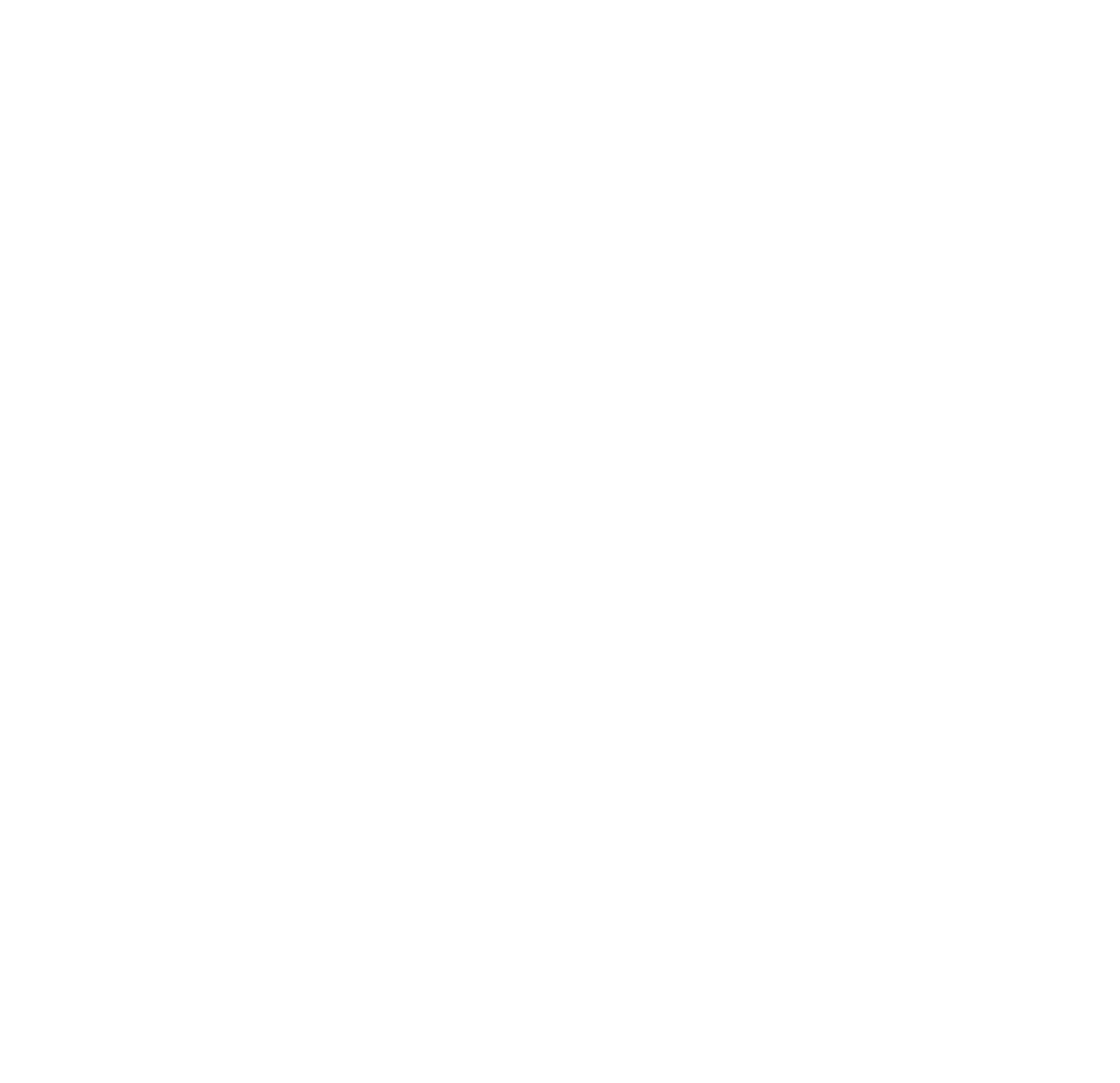


International Journal of Multimedia and Ubiquitous Engineering

V ol.11, No.1 (2016)

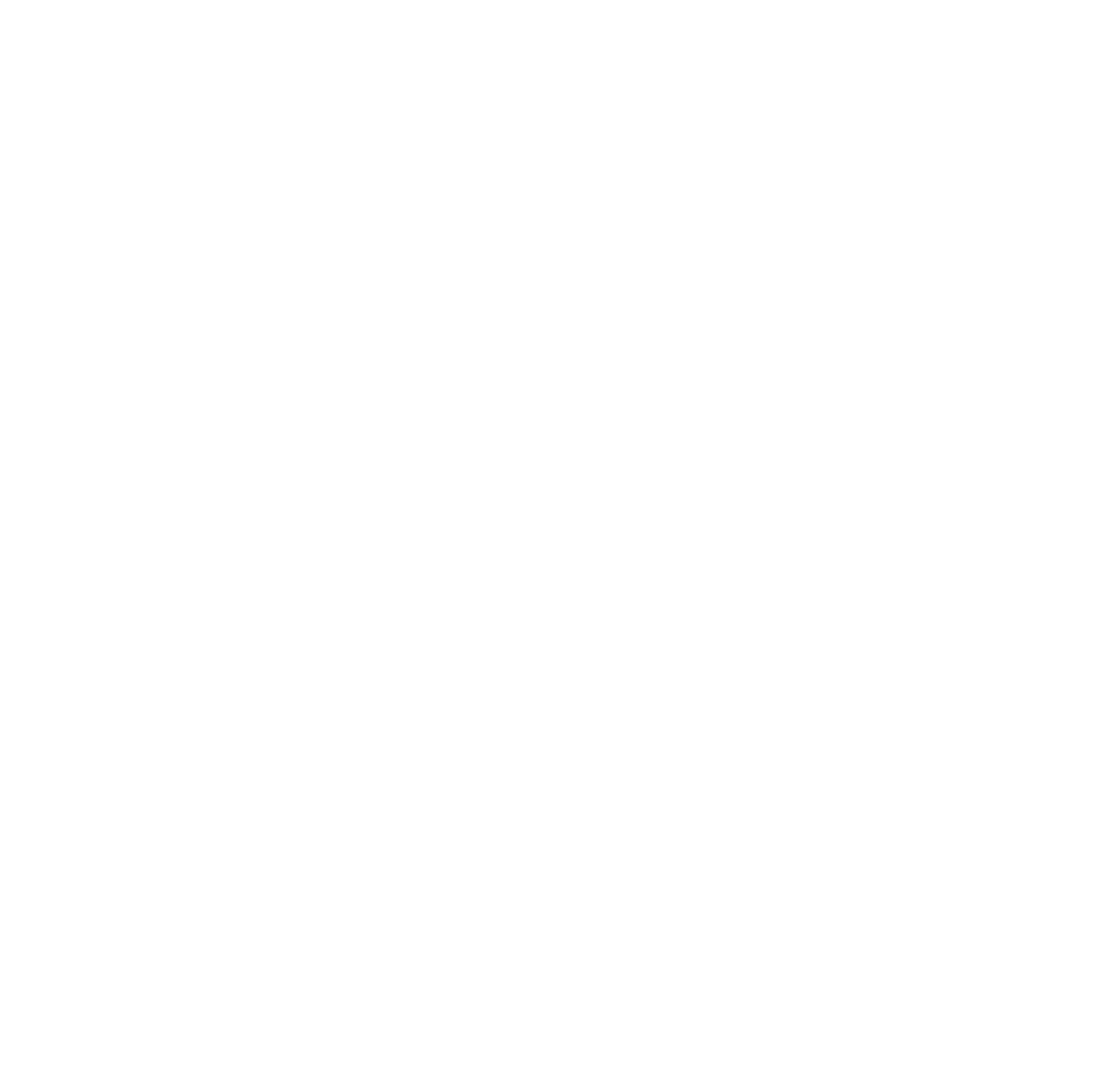

